\title{
O comportamento dos salários, pessoal ocupado e número de estabelecimentos dos setores science-based e supplier-dominated na economia brasileira nas últimas quatro décadas
}

\section{O comportamento dos Salários}

Walter Tadabiro Shima* Armando João Dalla Costa**

A variação da participação dos salários dos setores science-based (SB) e supplier-dominated (SD) no total nos períodos 1966-1995 e 1996-2003 é bastante pequena. Conforme a tabela 1, a participação dos salários dos setores SB no total cresceu 1,02\% em detrimento dos setores SD $(-0,27 \%)$ no período $1966-95$ e decresceu $-0,09 \%$ em favor dos SD $(0,04 \%)$ no período 1996-2003. Essa pequena variação positiva do período 1966-1995 se deve à maior participação dos salários nos setores SB no período 1981-1989, que foi de 5,70\% em detrimento da participação dos salários no total dos setores SD que foi de $-1,37 \%$. Isso segue a mesma tendência do crescimento da participação dos setores SB no total do Valor de Transformação Industrial (VTI) na economia brasileira ${ }^{48}$. Em outros termos, a participação dos salários segue relativamente estacionada ao longo dos períodos em análise (1966-1995 e 1996-2003), justamente por conta de que a economia brasileira incorpora relativamente pouco os setores SB (visto pela evolução da participação desses setores no total do VTI). Portanto, obviamente se os setores SB crescem pouco no Brasil, não há como crescer mais ainda os salários. Nesse sentido, é verdade como se afirmou no Boletim anterior, que os setores SB cresceram na economia brasileira, porém, relativamente pouco. Portanto, a participação dos salários desses setores permanece estável, indicando também que os mesmos não tiveram ganhos de produtividade. Trata-se de uma situação estacionária da série das participações dos salários no total dos setores SB e SD, conforme mostram os gráficos 1 e 2.

\footnotetext{
* Doutor em Economia pela Universidade Federal do Rio de Janeiro (IE/UFRJ). Professor do Departamento de Economia da Universidade Federal do Paraná (UFPR). Endereço eletrônico: waltershima@ufpr.br

** Doutor em Economia pela Université de Paris III (Sorbonne-Nouvelle). Professor do Departamento de Economia da Universidade Federal do Paraná (UFPR). Endereço eletrônico: ajdcosta@ufpr.br

48 Conforme analisado na Vol. 03 do Boletim de Economia \& Tecnologia, a participação dos setores SB no total do VTI da economia brasileira no período 1966-1995 cresceu apenas 1,05\%, em detrimento dos setores SD que decresceram 0,74\%; e no período 1996-2003 a participação dos SB cresceu 0,74\% em detrimento dos SD que decresceram - $0,32 \%$. Note-se que é a participação dos salários dos setores SB no total é próxima à participação do VTI no total do mesmo setor.
} 
Tabela 1. Taxa de crescimento médio dos setores SB e SD na participação dos Salários nos períodos 1966-1995 e 1996-2003 - Brasil

\begin{tabular}{lcc}
\hline Períodos & SB & SD \\
\hline $1966 / 79$ & $-1,13 \%$ & $0,23 \%$ \\
$1981 / 89$ & $5,70 \%$ & $-1,37 \%$ \\
$1981 / 95$ & $2,97 \%$ & $-0,71 \%$ \\
$1966 / 95$ & $1,02 \%$ & $-0,27 \%$ \\
$1996 / 03$ & $-0,09 \%$ & $0,04 \%$ \\
\hline
\end{tabular}

Fonte: elaborado pelos autores a partir de dados do IBGE.

Gráfico 1. Evolução da participação dos setores SB e SD no total dos salários pagos no período 1966-1995 - Brasil

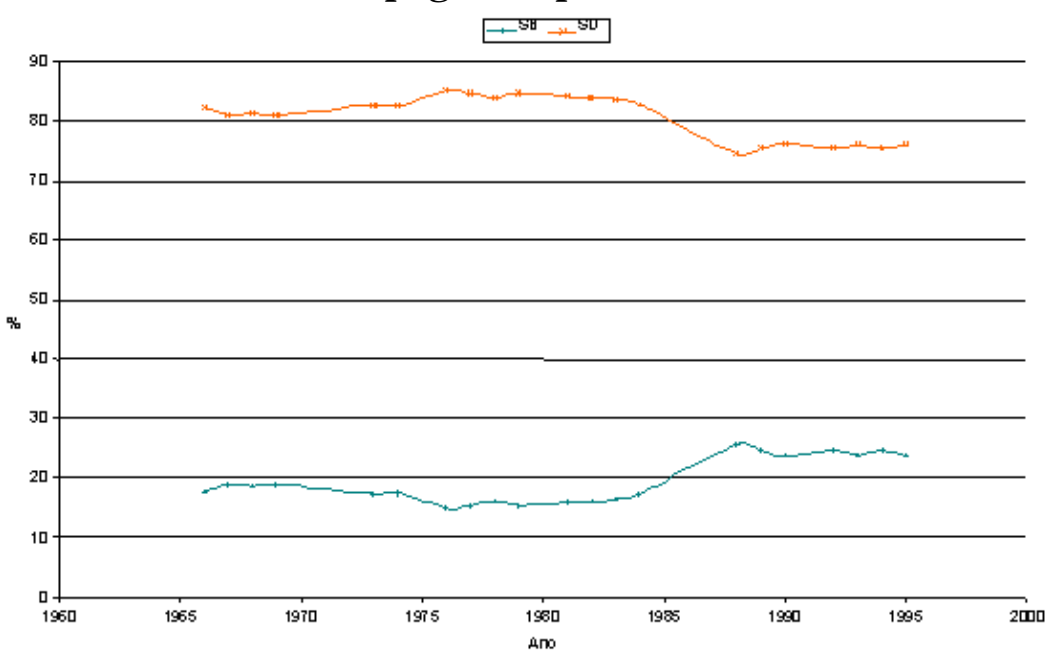

Fonte: elaborado pelos autores a partir de dados do IBGE.

Gráfico 2. Evolução da participação dos setores SB e SD no total de salários, retiradas e outras remunerações no período 1996-2003 - Brasil

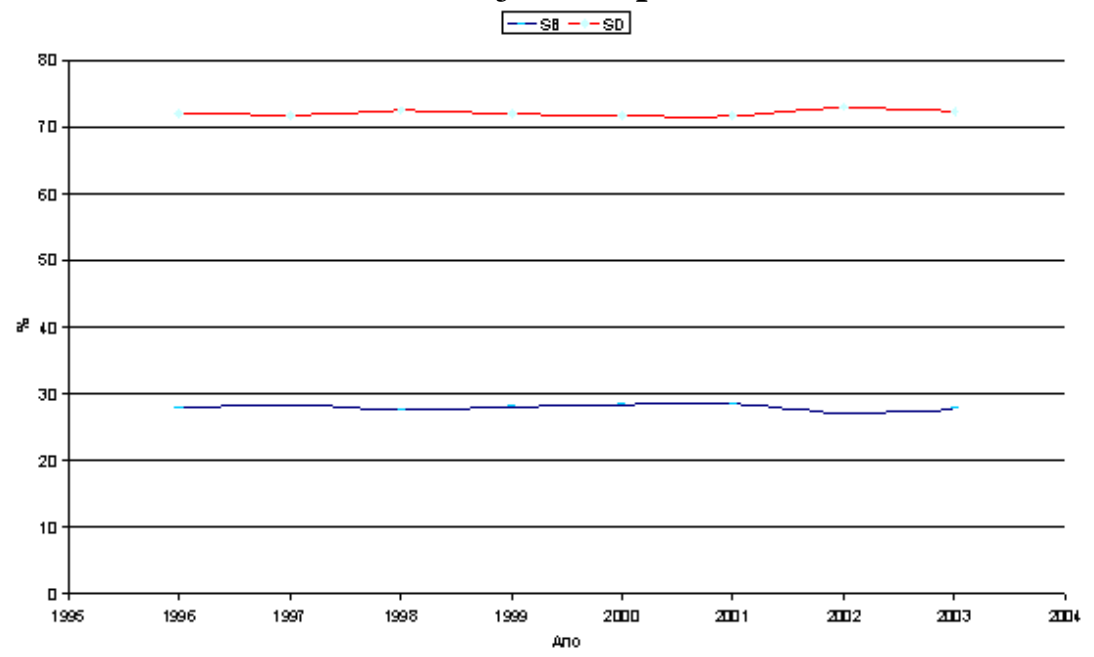

Fonte: elaborado pelos autores a partir de dados do IBGE. 


\section{O comportamento do Pessoal ocupado}

Da mesma forma que os salários o emprego acompanhou a evolução da produção (VTI) dos setores SB e SD. Conforme a tabela 2, a participação do pessoal ocupado no total dos setores SB cresceu $1,02 \%$ em detrimento dos setores SD que decresceu $-0,18 \%$ no período 1966-1995 e no período 1996-2003 a participação dos setores SD decresceu -1,38\%, em favor dos setores SD que cresceu 0,31\%. Obviamente isso segue o mesmo comportamento dos salários em função do baixo crescimento da participação dos setores SB no total do VTI. Basicamente o crescimento positivo dos setores SB no período 1966-1995 decorre do importante crescimento no período $1981 / 89$ (6,89\%), da mesma forma como ocorreu com os salários (5,70\%). Note-se também nos gráficos 3 e 4 como a variação do pessoal ocupado evoluiu da mesma forma que os salários (gráfico 1 e 2).

Entretanto, deve-se destacar que uma vez que os setores SB seriam os que geram efeitos de spill-over para toda a economia, é de se esperar que eles estejam incorporando os ganhos de produtividade gerados nos próprios setores. Como se trata de setores intensivos em conhecimento é muito provável que de fato o crescimento da participação do seu VTI no total não seja acompanhado num mesmo ritmo do emprego e dos salários. Mesmo, a princípio, implicando empregos mais qualificados nos setores $\mathrm{SB}$, os relativamente poucos que conseguem se empregar nesse setor, não estariam recebendo salários relativamente maiores. Em outros termos, os setores SB cresceriam pouco, mas isso não implicaria minimamente aumento do emprego e massa salarial por conta de que incorporam amplamente os ganhos de produtividade que repassam aos demais setores da economia.

Tabela 2. Taxa de crescimento médio dos setores SB e SD na participação do Pessoal ocupado nos períodos 1966-1995 e 1996-2003 - Brasil

\begin{tabular}{lcc}
\hline Períodos & SB & SD \\
\hline $1966 / 79$ & $-0,90 \%$ & $0,13 \%$ \\
$1981 / 89$ & $6,89 \%$ & $-1,09 \%$ \\
$1981 / 95$ & $3,62 \%$ & $-0,57 \%$ \\
$1966 / 95$ & $1,02 \%$ & $-0,18 \%$ \\
$1996 / 03$ & $-1,38 \%$ & $0,31 \%$ \\
\hline
\end{tabular}

Fonte: elaborado pelos autores a partir de dados do IBGE. 
Gráfico 3. Evolução da participação dos setores SB e SD no total do Pessoal ocupado no período 1966-1995 - Brasil

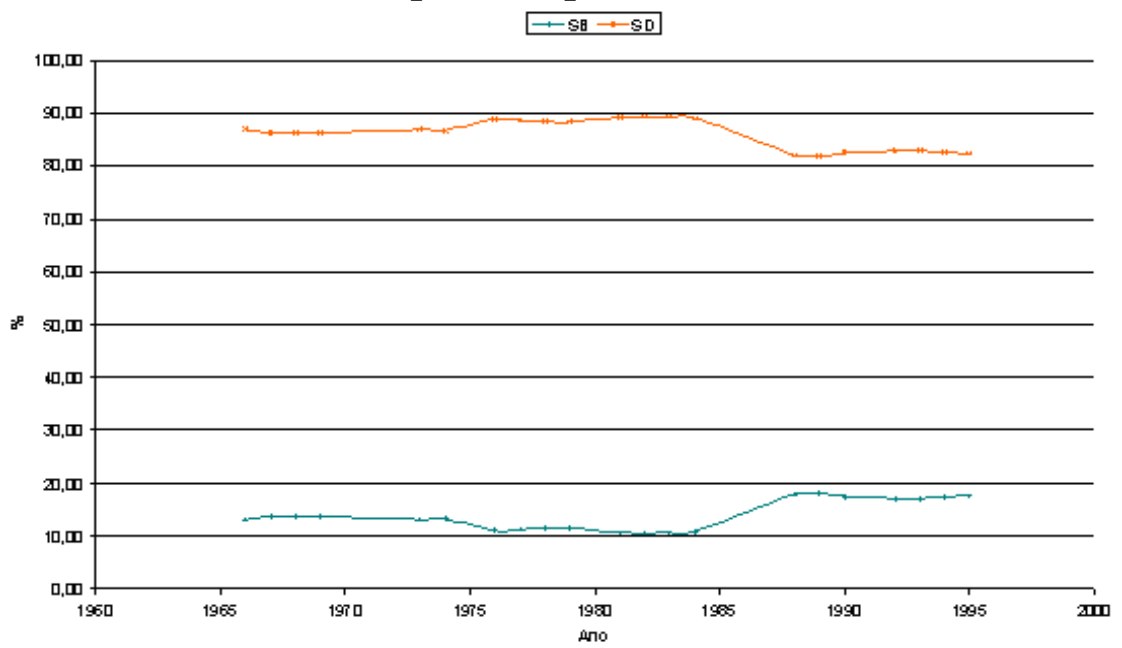

Fonte: elaborado pelos autores a partir de dados do IBGE.

Gráfico 4. Evolução da participação dos setores SB e SD no total do Pessoal ocupado no período 1996-2003 - Brasil

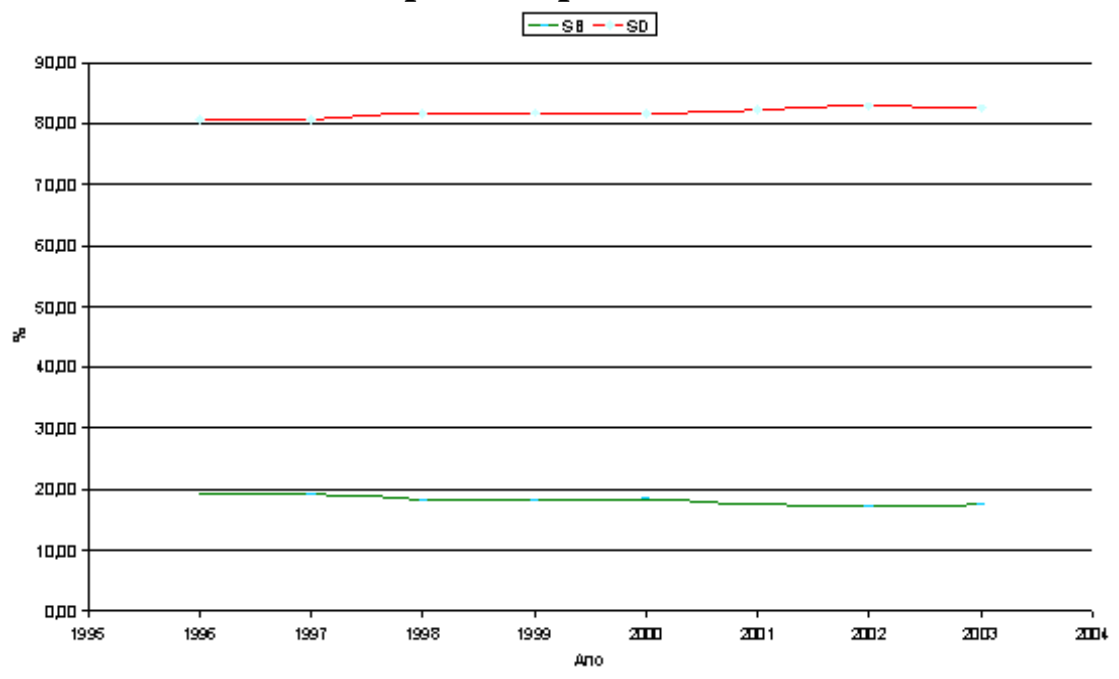

Fonte: elaborado pelos autores a partir de dados do IBGE.

\section{O comportamento do número de estabelecimentos}

O número de estabelecimentos já apresenta um comportamento diferente dos salários e pessoal ocupado. Conforme a tabela 3, a participação dos setores SB no total de estabelecimentos cresceu 3,61\% em detrimento dos setores SD que decresceram $-0,45 \%$ no período 1966-95 e no período 1996-2003 a participação dos setores SB cresceu apenas 0,82\% em detrimento dos setores SD cuja participação decresceu $0,11 \%$. Essa variação positiva da participação dos setores SB é explicada pelo importante crescimento no período 1981/89 de 12,56\%. Considerando essas variações é possível afirmar que o número de estabelecimentos 
sofreu uma mudança significativa. Em outros termos, proliferaram a partir dos anos 1980 estabelecimentos ligados a atividades pertencentes ao novo paradigma tecnológico ${ }^{49}$. Conforme a literatura sobre o desenvolvimento tecnológico atual, trata-se de uma forma de desenvolvimento em que se abrem novas oportunidades de negócios para pequenas e médias empresas não só SD, mas também pequenas e médias empresas capazes de serem SB.

Nesse sentido, por conta dos dados sobre emprego e salários, esses novos estabelecimentos contratariam muito pouco e os poucos contratados receberiam salários relativamente baixos $^{50}$. Os gráficos 5 e 6 apresentam a tendência do número de estabelecimentos para os períodos selecionados. Nota-se que no período 1966-1995 os setores $\mathrm{SB}$ cresceram mais em relação aos setores $\mathrm{SD}$.

Tabela 3. Taxa de crescimento médio dos setores SB e SD na participação do Número de estabelecimentos pessoal ocupado nos períodos 1966-1995 e 1996-2003 - Brasil

\begin{tabular}{ccc}
\hline Período & SB & SD \\
\hline $1966 / 79$ & $1,84 \%$ & $-0,14 \%$ \\
$1981 / 89$ & $12,56 \%$ & $-1,52 \%$ \\
$1981 / 95$ & $7,09 \%$ & $-0,89 \%$ \\
$1966 / 95$ & $3,61 \%$ & $-0,45 \%$ \\
$1996 / 03$ & $0,82 \%$ & $-0,11 \%$ \\
\hline
\end{tabular}

Fonte: elaborado pelos autores a partir de dados do IBGE

Gráfico 5. Evolução da participação dos setores SB e SD no total de Número de estabelecimentos no período de 1966-1995 - Brasil

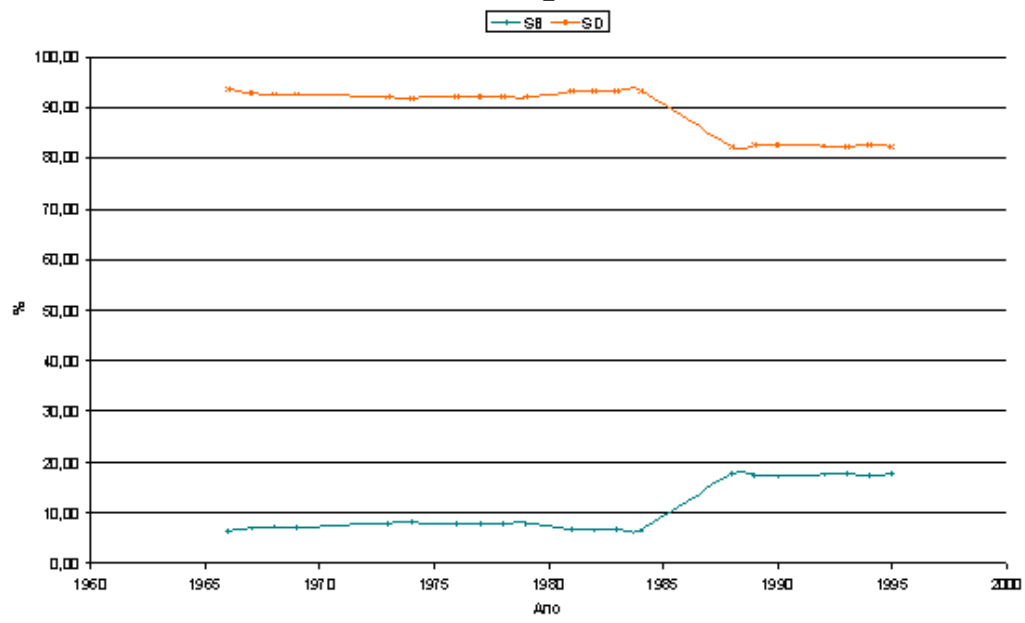

Fonte: elaborado pelos autores a partir de dados do IBGE

\footnotetext{
${ }^{49}$ Em pesquisa recente do Instituto Paranaense de Desenvolvimento Econômico e Social (IPARDES) sobre os setores de serviços no Paraná, constatou-se que grande parte das empresas cujos empregos exigem elevado grau de qualificação formal, foram fundadas muito recentemente. Trata-se de empresas cujas atividades se relacionam ao novo paradigma tecnológico, tais como, software, serviços de assessoria, telecomunicações, P\&D, design, etc.

${ }^{50}$ A pesquisa do IPARDES referida na nota anterior constata isso também. Trata-se de pequenas empresas com elevada qualificação formal composta pelo proprietário e alguns técnicos.
} 


\section{Gráfico 6. Evolução da participação dos setores SB e SD no total de} Número de estabelecimentos no período 1996-2003 - Brasil

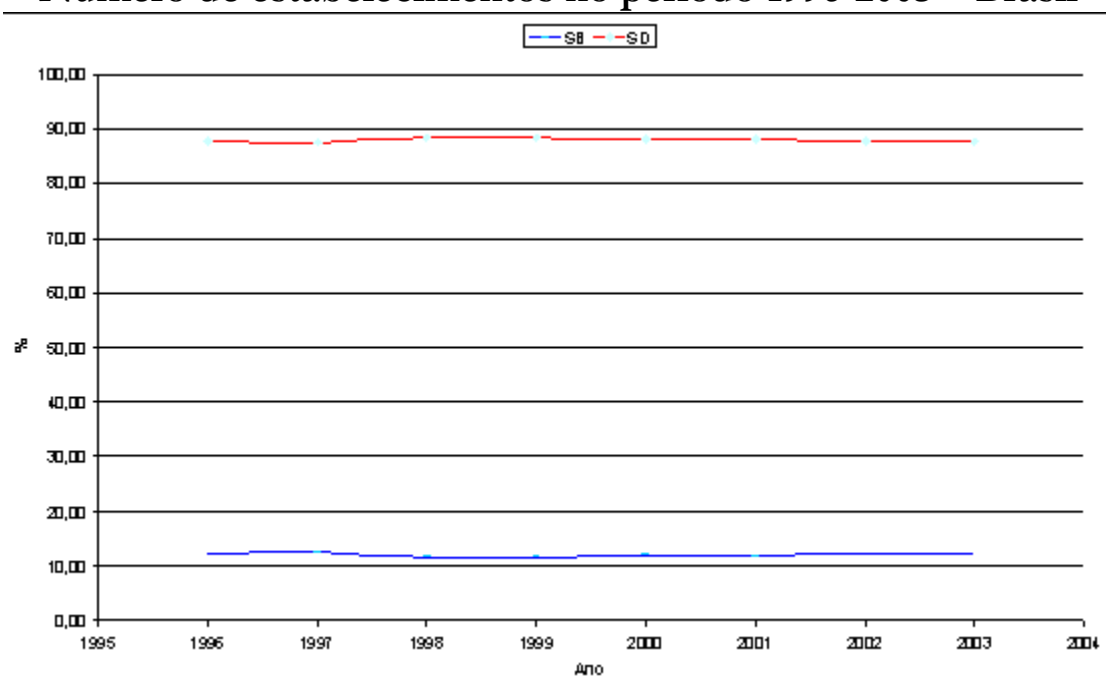

Fonte: elaborado pelos autores a partir de dados do IBGE.

Resumindo, pode-se afirmar que a participação dos salários segue relativamente estacionada ao longo dos dois períodos em análise (1966-1995 e 1996-2003), justamente por conta de que a economia brasileira incorpora relativamente pouco os setores SB. Da mesma forma que os salários, o emprego acompanhou a evolução da produção (VTI) dos setores SB e SD. Destaque-se ainda o fato da expectativa a respeito da geração de efeitos spill-over para toda economia dos setores SB e que os mesmos estejam incorporando os ganhos de produtividade gerados nos próprios setores.

No que se refere ao número de estabelecimentos, proliferaram a partir dos anos 1980, os que estão ligados ao novo paradigma tecnológico. Resgatando a atual literatura sobre o tema do desenvolvimento tecnológico, pode-se afirmar que se trata de desenvolvimento em que se abrem novas oportunidades de negócios para pequenas e médias empresas, não só SD, mas também pequenas e médias empresas capazes de serem SB. 